\title{
Efficacy of ultra-early rehabilitation on elbow function after Slongo's external fixation for supracondylar humeral fractures in older children and adolescents
}

\author{
Man $\mathrm{He}^{1 \dagger}$, Qian Wang ${ }^{2+}$, Jingxin Zhao ${ }^{2}$ and Yu Wang ${ }^{2^{*}}$ (D)
}

\begin{abstract}
Objective: To evaluate the efficacy of ultra-early rehabilitation on elbow function after Slongo's external fixation for supracondylar humeral fractures in older children and adolescents.

Methods: We retrospectively analyzed clinical data from 49 older children (> 8 years) and adolescents with supracondylar humerus fracture who were treated with Slongo's external fixation in our hospital from January 2016 to August 2020. Twenty-three patients received ultra-early postoperative rehabilitation (rehabilitation group) and 26 patients were not subjected to postoperative rehabilitation (control group). Time to ROM required for functional activity of daily living(ROM-ADL) in both groups was recorded postoperatively. Patients were followed up at 3 and 6 months after surgery to compare the elbow range of motion (ROM) and carrying angle (CA). Postoperative complications were assessed in both groups. Flynn scores and modified Mayo Elbow Performance Scores were also performed.

Results: The elbow function at 6 months after surgery was significantly better than that at 3 months in the control group ( $P=0.32$ ). Time to ROM-ADL in the rehabilitation group was significantly shorter than that of the control group $(P=0.028)$. The elbow function, Flynn scores, and modified Mayo scores in the rehabilitation group at 3 and 6 months after surgery were significantly better than that of the control group ( $P(\mathrm{ROM}, 3$ months and 6 months) $=$ 0.012 vs $0.039 ;$ P(Flynn scores, ROM, 3 months and 6 months $)=0.028$ vs 0.005; P(Flynn scores, CA, 3 months and 6 months) $=0.032$ vs 0.026; $P$ (Modified Mayo scores, 3 months and 6 months) $=0.039$ vs 0.024; respectively). There were no iatrogenic injuries, secondary fracture displacements, myositis ossificans, elbow deformities, or other complications in either group. One case of nail tract infection occurred in the rehabilitation group and was cured.

Conclusion: Slongo's external fixation is a safe and effective surgical treatment for supracondylar humeral fractures in children over 8 years old and adolescents. Ultra-early rehabilitation treatment for postoperative children can significantly speed up the recovery after surgery.
\end{abstract}

Keywords: Supracondylar humeral fracture, Older children, Adolescent, Rehabilitation, External fixation

\footnotetext{
* Correspondence: w741366430@126.com

${ }^{\dagger} \mathrm{Man}$ He and Qian Wang are co-first authors.

${ }^{2}$ Trauma Department of Orthopedics, Affiliated Hospital of Chengde Medical

College, 36 Nanyingzi Street, Shuangqiao District, Chengde, Hebei 067000,

People's Republic of China

Full list of author information is available at the end of the article
}

(c) The Author(s). 2021 Open Access This article is licensed under a Creative Commons Attribution 4.0 International License, which permits use, sharing, adaptation, distribution and reproduction in any medium or format, as long as you give appropriate credit to the original author(s) and the source, provide a link to the Creative Commons licence, and indicate if changes were made. The images or other third party material in this article are included in the article's Creative Commons licence, unless indicated otherwise in a credit line to the material. If material is not included in the article's Creative Commons licence and your intended use is not permitted by statutory regulation or exceeds the permitted use, you will need to obtain permission directly from the copyright holder. To view a copy of this licence, visit http://creativecommons.org/licenses/by/4.0/ The Creative Commons Public Domain Dedication waiver (http://creativecommons.org/publicdomain/zero/1.0/) applies to the data made available in this article, unless otherwise stated in a credit line to the data. 


\section{Introduction}

Supracondylar humeral fracture is the most common elbow fracture in children. It usually occurs in children between the ages of 5 and $7[1,2]$. Supracondylar humeral fractures can be divided into extension and flexion fractures and approximately $97 \%$ are extension type fractures [3]. Supracondylar humeral fractures are commonly divided into three types according to the modified Gartland classification, while surgical treatment is recommended for Gartland II and III fractures in children [4]. The incidence of supracondylar humeral fractures in children has increased by $28 \%$ in the past decade [5], while the surgical rate has also increased [6]. There are several surgical techniques including K-wire, corticoid screw, and elastic intramedullary nail [7, 8]; however, the standard surgical treatment for displaced pediatric supracondylar humeral fractures is closed reduction and percutaneous pinning (CRPP), with the placement of a postoperative plaster cast $[9,10]$. The elbow joint movement can be restricted to varying degrees after the removal of the plaster cast. Interestingly, children tend to not move the affected limb due to fear or pain. Therefore, the occurrence of elbow joint stiffness after surgery has become a concern of parents. For older children and adolescents, the recovery period is prolonged, and the risk of joint stiffness increases [11]. As a relatively new surgical method, external fixation has become a treatment choice for supracondylar humeral fracture in older children and adolescents. Indeed, this technique can enable children and adolescents to perform early elbow joint functional exercises after surgery, thus reducing the risk of elbow stiffness.

Therefore, the purpose of this study was to assess the effects of Slongo's external fixation in the treatment of supracondylar humeral fractures in older children and adolescents. Moreover, we sought to assess the clinical value of ultra-early rehabilitation after external fixation operation in older children and adolescents.

\section{Methods \\ Patients}

We retrospectively analyzed clinical data of 49 older children (> 8 years) and adolescents with supracondylar humeral fractures who were treated with closed reduction and Slongo's external fixation in our hospital from January 2016 to August 2020. A total of 23 patients were subjected to ultra-early postoperative rehabilitation (rehabilitation group), while 26 patients without postoperative rehabilitation were served as the control group. Children with open fractures, coexisting fractures of other parts, and injuries of other organs were excluded. Health education on disease, operation, and rehabilitation was carried out for children and their parents during the perioperative period. The informed consent of the parents was obtained prior to inclusion in the study.

\section{Surgical procedures}

The operation was performed under general anesthesia. The patient was in the supine position and the fracture reduction was performed with a C-arm fluoroscopy. Distal 4.0-mm Schanz screw was used and was located above the external humeral condyle epiphyseal plate and in the rotation center of the elbow joint. The surgeon was careful to avoid screw injury to the epiphyseal and epiphyseal plate of the lateral condyle and to prevent the screw from entering the coronal fossa, olecranon fossa, and breaking through the cortex of the distal medial humerus. A proximal Schanz screw with a diameter of 4.0 $\mathrm{mm}$ was directly drilled into the humerus after a small incision. A sleeve was used to protect the surrounding soft tissue while drilling, and the screw was positioned at the center of the humerus. After the closed reduction was made, a connecting rod was used to fix the screws. Finally, a $1.8-\mathrm{mm}$ or $2.0-\mathrm{mm}$ Kirschner wire was inserted in the lateral condyle of the humerus to prevent rotation of the fracture end, with care to not limit elbow movement. Postoperative plaster casts were not used (Fig. 1).

\section{Postoperative rehabilitation \\ Rehabilitation group}

The rehabilitation team of our hospital (including rehabilitation doctors, physical therapists, and occupational therapists) performed a postoperative systematic rehabilitation treatment. Active and passive activity training of adjacent joints on the day after surgery were performed, with active flexion and extension exercises of the affected shoulder, wrist, metacarpophalangeal joint, and interphalangeal joint. Elbow joint loosening + progressive resistance training $(30 \mathrm{~min} /$ day, starting on the second day after surgery) was performed through passive flexion and extension of the elbow on the affected side. The elbow resistance training with an elastic band was performed starting 3 days after surgery on the premise that the patient had no significant pain. Wax therapy (15 min/day, performed before elbow joint loosening) was also conducted, using an appropriate wax size wax to wrap the elbow above $1 \mathrm{~cm}$ away from the Schanz screws. Occupational therapy $(30 \mathrm{~min} \times 2 /$ day $)$ was started 3 days after surgery and the child's upper limbs were treated with fun occupational therapy using a RAMGUIDER upper limb rehabilitation training system, in which a suitable upper limb movement goal for the patient's joint range of motion was set and, if painless, the overall active movement ability of the affected upper limb progressively increased through purpose-oriented training. The movement mode was adjusted according 


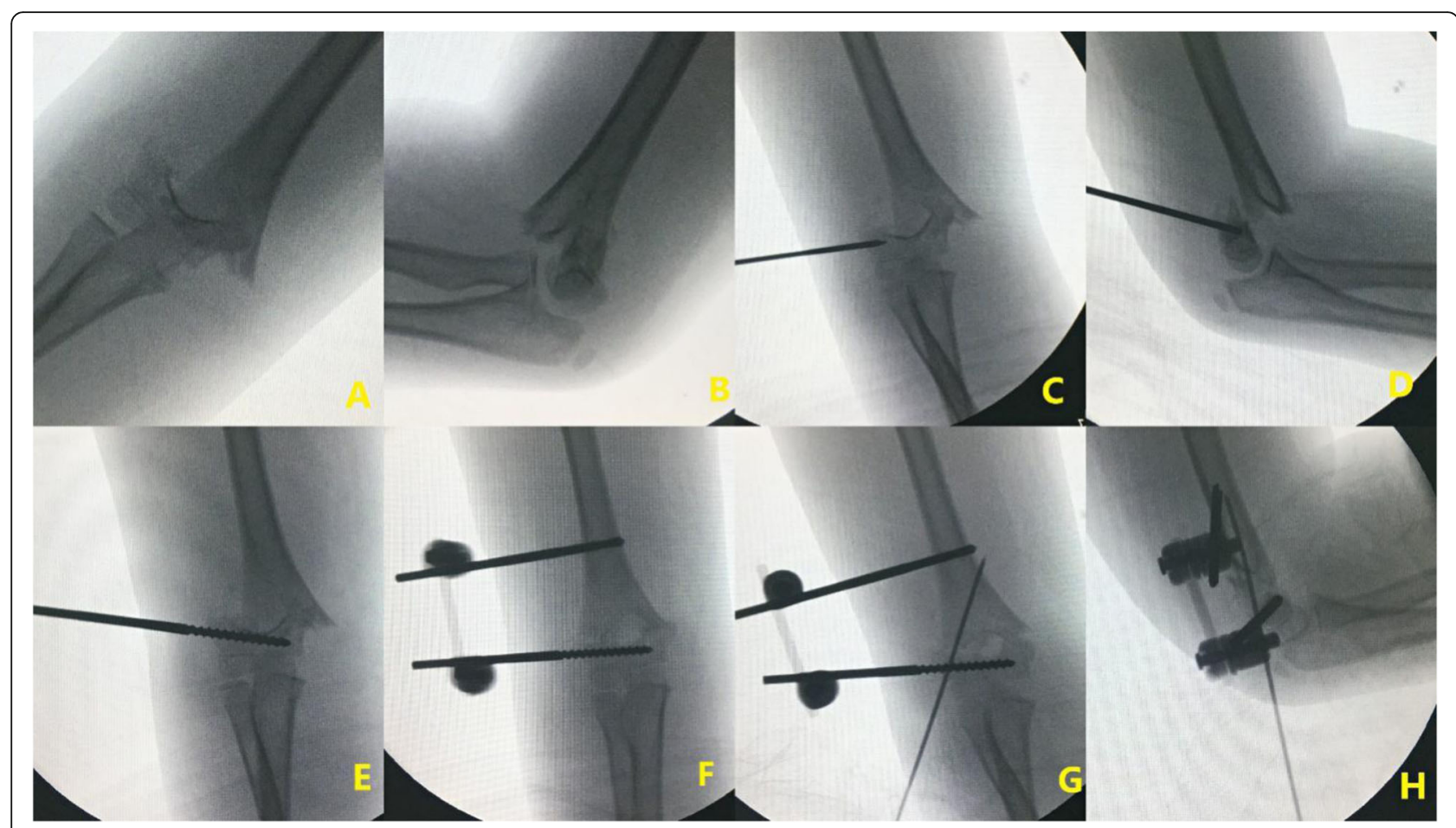

Fig. 1 Preoperative X-ray radiographs (A, B); location and placement of the distal Schanz screw (C-E); placement of proximal Schanz screw (F); anteroposterior and lateral $\mathrm{X}$-ray radiographs after anti-rotating Kirschner wire placement $(\mathbf{G}, \mathbf{H})$

to the patient's measured elbow joint range of motion every day. Lymphatic drainage of the affected limb (15 $\mathrm{min} /$ day) was performed by the physiotherapist on the affected upper limb of the patient after joint loosening and active resistance training every day. Finally, cold therapy ( $15 \mathrm{~min} /$ day) was performed after the abovementioned treatments were finished. Attention was paid to avoid secondary fracture displacements and the occurrence of myositis ossificans. The rehabilitation treatment lasted for 2 weeks, 6 days per week. After the patient and their parents had mastered the exercise methods, they were instructed to conduct exercises at home.

The control group did not receive ultra-early rehabilitation treatment after surgery. Patients that met the discharge criteria were discharged from the hospital and underwent self-rehabilitation training at home.

When discharged from the hospital, patients and parents in both groups were required to add a review WeChat public account to communicate with surgeons and rehabilitation doctors about their rehabilitation and exercises at any time through the form of WeChat video, so that they could receive timely guidance. Educational booklets for exercise in postoperative rehabilitation were given to the patients in both groups. Regular outpatient follow-up was conducted and suggestions on postoperative rehabilitation were given. The external fixation was removed after fracture healing.

\section{Follow-up indicators}

Follow-up clinical examination and X-rays were taken at 3 and 6 months after the surgery. Range of motion (ROM), time to ROM required for functional activity of daily living (ROM-ADL), and carrying angle (CA) of the elbow were recorded. ROM-ADL was defined as $30^{\circ}$ of extension, $130^{\circ}$ of flexion [12]. Postoperative complications such as infection, iatrogenic nerve injury, ischemic contracture, myositis ossificans, and elbow varus/valgus deformities were monitored. Flynn scores and modified Mayo elbow function scores were performed for both groups.

\section{Statistical methods}

The SPSS22.0 software was used to process the data. Measurement data were expressed as $x^{2} \pm S$. Paired $t$ tests were used for comparisons of normally distributed data, while independent sample $t$-test was used for comparison between groups. Non-parametric chi-square was used to compare data that did not conform to a normal distribution. $P<0.05$ was considered statistically significant.

\section{Results}

There was no significant difference in basic information such as age, sex, height, and weight between the two groups $(P>0.05)$, as shown in Table 1 . The elbow function of children in the control group showed a gradual 
Table 1 Basic information of two groups

\begin{tabular}{|c|c|c|c|}
\hline Group & The control group & Rehabilitation group & $P$ \\
\hline 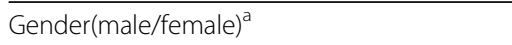 & $16: 10$ & $11: 12$ & 0.564 \\
\hline Age (years) & $10.58 \pm 1.68$ & $11.14 \pm 1.52$ & 0.892 \\
\hline Height (cm) & $121.33 \pm 21.991$ & $108.39 \pm 23.259$ & 0.860 \\
\hline Weight (kg) & $32.95 \pm 16.96$ & $35.63 \pm 12.68$ & 0.140 \\
\hline Affected side (left / right) & $9: 17$ & $8: 15$ & 0.470 \\
\hline Type $^{a}$ & & & 0.284 \\
\hline Gartland II & $10(38.46 \%)$ & $6(26.09 \%)$ & \\
\hline Gartland III & $16(61.54 \%)$ & $17(73.91 \%)$ & \\
\hline Time from admission to operation (h) & $35.81 \pm 27.958$ & $59.69 \pm 38.969$ & 0.151 \\
\hline Hospitalization time (days) & $3.81 \pm 0.168$ & $4.78 \pm 0.257$ & 0.807 \\
\hline Operation time (min) & $49.09 \pm 4.153$ & $50.62 \pm 3.375$ & 0.625 \\
\hline Number of intraoperative fluoroscopy (time) & $23.81 \pm 2.827$ & $22.97 \pm 1.858$ & 0.416 \\
\hline Time to ROM-ADL (week) & $6.65 \pm 0.80$ & $9.74 \pm 1.25$ & 0.028 \\
\hline
\end{tabular}

${ }^{a}$ Chi-square test

improvement at 3 and 6 months $(P<0.05$, Table 2$)$. Time to ROM-ADL in the rehabilitation group was significantly shorter than that of the control group ( $P$ $<0.05$, Table 1). The elbow function, Flynn scores, and modified Mayo scores of the elbow in the rehabilitation group at 3 and 6 months after surgery were significantly better than those of the control group $(P<0.05$, Tables 2,3 , and 4$)$. One case of nail tract infection occurred in the rehabilitation group, which was a superficial pin tract infection around the proximal Schanz screw. After local dressing changes for 1 week, the patient recovered. We detected no cases of pin tract infection with the anti-rotation wire. No cases of deep infection or osteomyelitis occurred. All patients with preoperative nerve injury recovered spontaneously after surgery. There were no other iatrogenic injuries, myositis ossificans, secondary fracture displacement, elbow deformities, or other complications in either group.
Discussion

Application of external fixation in the treatment of supracondylar humeral fracture in older children and adolescents

The aim of the treatment of displaced supracondylar humeral fractures in children is to achieve a satisfactory reduction and firm fixation so that fractures can heal successfully, thus reducing the risk of iatrogenic injuries and complications. Closed reduction and percutaneous pinning is the standard treatment for supracondylar humeral fractures in children. Percutaneous pinning may be appropriate for younger children, but for older children (> 8 years old) and adolescents that have a larger body weight, there is an increased risk of secondary fracture displacement and elbow stiffness due to the limited fixed strength of the Kirschner wire and the need for supplementary plaster cast.

External fixation is a surgical alternative for supracondylar humeral fractures and was first proposed by Taller

Table 2 Comparison between the control group and the rehabilitation group after external fixator operation

\begin{tabular}{|c|c|c|c|c|c|c|c|}
\hline \multirow{3}{*}{$n$} & \multicolumn{2}{|c|}{ The control group } & \multicolumn{2}{|c|}{ Rehabilitation group } & \multirow[t]{3}{*}{$P_{1}$} & \multirow[t]{3}{*}{$P_{2}$} & \multirow[t]{3}{*}{$P_{3}$} \\
\hline & \multicolumn{2}{|l|}{26} & \multicolumn{2}{|l|}{23} & & & \\
\hline & $\begin{array}{l}3 \text { months after } \\
\text { surgery }\end{array}$ & $\begin{array}{l}6 \text { months after } \\
\text { surgery }\end{array}$ & $\begin{array}{l}3 \text { months after } \\
\text { surgery }\end{array}$ & $\begin{array}{l}6 \text { months after } \\
\text { surgery }\end{array}$ & & & \\
\hline Flexion in affected side $\left(^{\circ}\right)$ & $139.88 \pm 4.99$ & $141.62 \pm 6.81$ & $140.76 \pm 3.13$ & $143.71 \pm 3.26$ & 0.017 & 0.007 & 0.018 \\
\hline Contralateral flexion $\left(^{\circ}\right)$ & $146.25 \pm 3.64$ & $146.25 \pm 3.64$ & $146.23 \pm 4.25$ & $146.26 \pm 3.25$ & 0.89 & 0.92 & 1.46 \\
\hline $\begin{array}{l}\text { Extension in affected side } \\
\left({ }^{\circ}\right)\end{array}$ & $2.51 \pm 1.09$ & $2.04 \pm 0.76$ & $-1.23 \pm 0.69$ & $-2.29 \pm 0.29$ & 0.028 & 0.02 & 0.026 \\
\hline Contralateral extension $\left(^{\circ}\right)$ & $-2.56 \pm 1.01$ & $-2.56 \pm 1.01$ & $-2.66 \pm 2.45$ & $-2.76 \pm 2.25$ & 0.76 & 0.83 & 1.23 \\
\hline Total ROM ( $\left.{ }^{\circ}\right)$ & $137.08 \pm 1.72$ & $138.38 \pm 1.13$ & $140.09 \pm 2.61$ & $141.74 \pm 1.74$ & 0.012 & 0.039 & 0.032 \\
\hline $\mathrm{CA}\left({ }^{\circ}\right)$ & $4.89 \pm 0.82$ & $8.13 \pm 0.82$ & $6.52 \pm 1.66$ & $9.94 \pm 0.83$ & 0.038 & 0.032 & 0.022 \\
\hline
\end{tabular}

$P_{1}$, comparison of $P$ value between the two groups 3 months after surgery; $P_{2}, P$ value of the control group and the rehabilitation group 6 months after surgery; $P_{3}$, comparison of $P$ values between the rehabilitation group 3 months after surgery and the rehabilitation group 6 months after surgery 
Table 3 Comparison of Flynn scores in two groups

\begin{tabular}{|c|c|c|c|c|c|c|c|}
\hline \multirow[t]{2}{*}{ Flynn scores } & \multicolumn{2}{|c|}{ The control group } & \multicolumn{2}{|c|}{ Rehabilitation group } & \multirow[t]{2}{*}{$P_{1}$} & \multirow[t]{2}{*}{$P_{2}$} & \multirow[t]{2}{*}{$P_{3}$} \\
\hline & $\begin{array}{l}3 \text { months after } \\
\text { surgery }\end{array}$ & $\begin{array}{l}6 \text { months after } \\
\text { surgery }\end{array}$ & $\begin{array}{l}3 \text { months after } \\
\text { surgery }\end{array}$ & $\begin{array}{l}6 \text { months after } \\
\text { surgery }\end{array}$ & & & \\
\hline$\overline{\text { According to } C A^{a}}$ & & & & & 0.032 & 0.026 & 0.04 \\
\hline Excellent & $1(3.8 \%)$ & $4(15.4 \%)$ & 9 (39.1\%) & $13(56.5 \%)$ & & & \\
\hline Good & $24(92.3 \%)$ & $21(80.8 \%)$ & $13(56.5 \%)$ & 9 (39.1\%) & & & \\
\hline Fair & $1(3.8 \%)$ & $1(3.8 \%)$ & $1(4.3 \%)$ & $1(4.3 \%)$ & & & \\
\hline Poor & 0 & 0 & 0 & 0 & & & \\
\hline $\begin{array}{l}\text { According to loss of ROM } \\
\text { a }\end{array}$ & & & & & 0.028 & 0.005 & 0.029 \\
\hline Excellent & $2(7.7 \%)$ & $6(23.1 \%)$ & 7 (30.4\%) & $12(52.2 \%)$ & & & \\
\hline Good & $23(88.5 \%)$ & $19(73.1 \%)$ & $15(65.2 \%)$ & $10(43.5 \%)$ & & & \\
\hline Fair & $1(3.8 \%)$ & $1(3.8 \%)$ & $1(4.3 \%)$ & $1(4.3 \%)$ & & & \\
\hline Poor & 0 & 0 & 0 & 0 & & & \\
\hline
\end{tabular}

$P_{1}$, comparison of $P$ value between two groups 3 months after surgery; $P_{2}, P$ value of the control group and the rehabilitation group 6 months after surgery; $P_{3}$ comparison of $P$ values between the rehabilitation group 3 months after surgery and the rehabilitation group 6 months after surgery

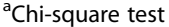

et al. [13]. Currently, there are three types of external fixation techniques used for supracondylar humeral fractures in children. The first type is an external fixation across the elbow to fix the proximal humerus fracture and the ulna, which was used by Gris [14] and Bogdan [15]. This form of fixation allows pronation and supination of the forearm; however, it does not allow flexion and extension of the elbow. The second type is the Ilizarov circular external fixation adopted by Gugenheim et al. [16]. In 2000, Gugenheim published satisfactory results in the treatment of supracondylar humeral fractures in children and adolescents. However, the operation technique of Ilizarov's external fixation is complex, which limits its application. The third form is the unilateral external fixation form invented by professor Slongo without fixing the elbow joint [17]. Two Schanz screws are placed and connected at each end of the supracondylar humeral fracture and an anti-rotation Kirschner wire is inserted laterally. This surgical technique is relatively simple and a biomechanical study has shown that Slongo's external fixation is more stable than the cross K-wire technique (Fig. 2) [18]. Indeed, the Schanz screw inserted can also assist in the reduction of fracture. Since 2016, Slongo's external fixation has been applied in our treatment of supracondylar humeral fractures in older children and adolescents, showing good therapeutic efficacy. However, we also found that some children and adolescents may refuse to move the injured elbow due to postoperative pain and fear, which hindered the recovery of elbow function. Surgeons should identify strategies to overcome these fears and improve treatment for these patients. It is inadvisable to immobilize the elbow after Slongo's external fixation since children with supracondylar humeral fractures can perform elbow activities after surgery that will improve their recovery.

\section{The significance of ultra-early rehabilitation in the treatment of supracondylar humeral fractures in older children and adolescents}

Rehabilitation medicine greatly advanced in the rehabilitation of adult orthopedic surgery, but it is still limited in the field of children orthopedics. It is still debatable whether postoperative rehabilitation is necessary for

Table 4 Comparison of postoperative modified Mayo scores in two groups

\begin{tabular}{|c|c|c|c|c|c|c|c|}
\hline \multirow{2}{*}{$\begin{array}{l}\text { Modified Mayo } \\
\text { scores }^{\text {a }}\end{array}$} & \multicolumn{2}{|c|}{ The control group } & \multicolumn{2}{|c|}{ Rehabilitation group } & \multirow{2}{*}{$\begin{array}{l}P_{1} \\
0.039\end{array}$} & \multirow{2}{*}{$\begin{array}{l}P_{2} \\
0.024\end{array}$} & \multirow{2}{*}{$\begin{array}{l}P_{3} \\
0.043\end{array}$} \\
\hline & $\begin{array}{l}3 \text { months after } \\
\text { surgery }\end{array}$ & $\begin{array}{l}6 \text { months after } \\
\text { surgery }\end{array}$ & $\begin{array}{l}3 \text { months after } \\
\text { surgery }\end{array}$ & $\begin{array}{l}6 \text { months after } \\
\text { surgery }\end{array}$ & & & \\
\hline Excellent & $2(7.7 \%)$ & $6(23.1 \%)$ & $7(30.4 \%)$ & $13(56.52 \%)$ & & & \\
\hline Good & $23(88.5 \%)$ & 19 (73.1\%) & $15(65.2 \%)$ & $9(39.13 \%)$ & & & \\
\hline Fair & $1(3.8 \%)$ & $1(3.8 \%)$ & $1(4.3 \%)$ & $1(4.3 \%)$ & & & \\
\hline Poor & 0 & 0 & 0 & 0 & & & \\
\hline
\end{tabular}

${ }^{\mathrm{a} C h i-s q u a r e ~ t e s t ~}$

$P_{1}$, comparison of $P$ value between two groups 3 months after surgery; $P_{2}, P$ value of the control group and the rehabilitation group 6 months after surgery; $P_{3}$ : Comparison of $P$ values between the rehabilitation group 3 months after surgery and the rehabilitation group 6 months after surgery 


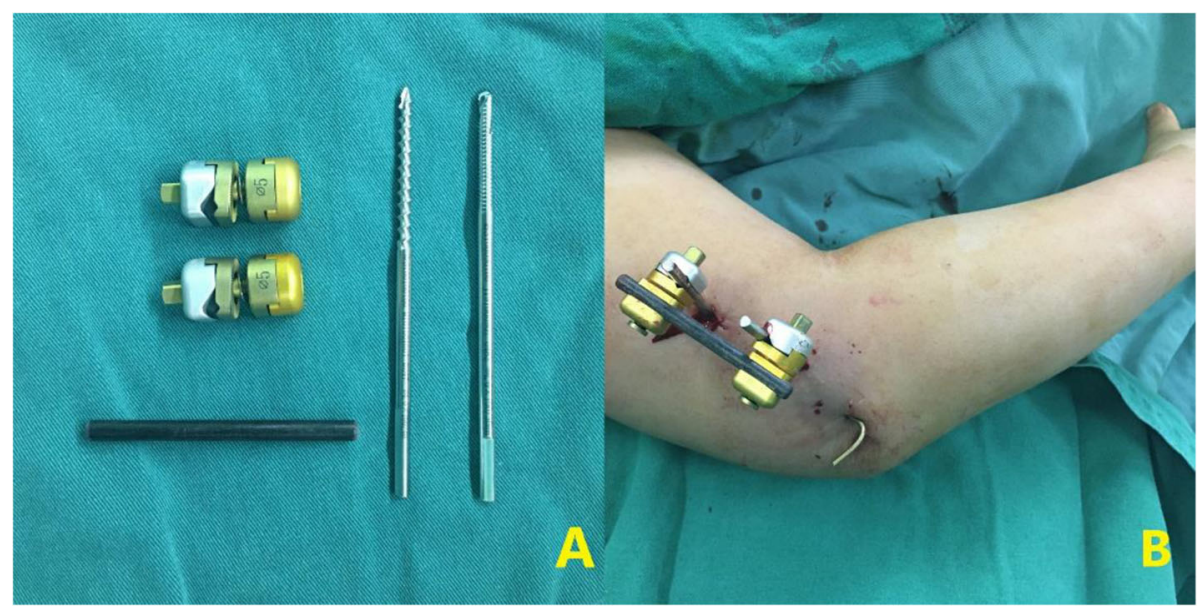

Fig. 2 Composition and postoperative appearance of Slongo's external fixation (A, B)

children with supracondylar humeral fractures [19]. The supporting view is that children with supracondylar humeral fractures should receive rehabilitation treatment as soon as possible after the end of immobilization of the affected limb to reduce the risk of elbow stiffness [20]. Colović et al. [21] analyzed changes in elbow function after supracondylar humeral fractures and the effects of early rehabilitation in children by measuring elbows range of motion and using a modified DASH questionnaire. They found that early rehabilitation of supracondylar humeral fractures in children results in significantly better elbow function and that rehabilitation should start within 15 days after removal of the immobilization. In this regard, Keppler et al. [22] also found that rehabilitation helped children with supracondylar humeral fractures recover faster and that it did not increase the risk of complications. The risk of elbow stiffness after a supracondylar humeral fracture is significantly increased in older children and adolescents. Therefore, children older than 8 years and adolescents should be treated differently from younger children. We found that older children and adolescents subjected to ultra-early rehabilitation recovered faster, which allows patients to return to normal life. Moreover, early rehabilitation may help to alleviate psychological pressure on patients and their parents. Compared with the traditional fixation form of pinning and plaster cast, the use of an external fixation enables patients to perform early elbow function exercises. The results of this study showed that older children and adolescents with an external fixation had a satisfactory recovery of elbow function without elbow stiffness. Moreover, because a plaster cast was not required after the surgery, the affected elbow was able to move within the acceptable range of the children and their comfort was significantly increased. The clinical treatment effect of ultra-early rehabilitation was satisfactory in the follow-up. We also noticed that the difference in elbow ROM at 6 months between the rehabilitation group and control group was statistically significant. However, the ROM of the elbow in both groups had reached the ROM required for functional activity of daily life, the difference in ROM had no discernable impact on function. Regardless of postoperative rehabilitation, we conclude that there may be no significant difference in the final elbow function between the two groups in long-term follow-up.

A key limitation of this study is that this is a retrospective analysis. The incidence of supracondylar humeral fractures is relatively low in older children and adolescents. Therefore, we plan to further expand the number of patients and apply more appropriate rehabilitation techniques to the treatment of supracondylar humeral fractures in older children and adolescents. Future studies will focus on how to make the elbow function of children recover better and faster, which is in line with the concept of Enhanced Recovery After Surgery (ERAS) [23].

\section{Conclusions}

Slongo's external fixation is a safe and effective surgical treatment for supracondylar humeral fractures in older children and adolescents. It allows early postoperative elbow movement, avoids elbow stiffness, and ensures good fracture healing. The ultra-early rehabilitation treatment for older children and adolescents after Slongo's external fixation can significantly speed up the recovery of the elbow joint, improve the quality of life of patients, and quickly enable them to return to normal life.

Abbreviations

ROM: Range of motion; CA: Carrying angle 


\section{Acknowledgements}

We thank all of the patients involved in the study.

\section{Authors' contributions}

YW contributed to the study design and is the corresponding author. $\mathrm{MH}$, $\mathrm{QW}$, and JZ contributed to the study design, data analysis and interpretation, and manuscript draft.MH and JZ contributed to the data collection and analysis. YW, QW, and $\mathrm{MH}$ contributed to the literature search and manuscript revision. All authors have read and approved the final manuscript.

\section{Funding}

No funding was provided.

\section{Availability of data and materials}

All data generated or analyzed during this study are included in this manuscript.

\section{Declarations}

Ethics approval and consent to participate

Ethics approval and consent to participate in present study was approved by the Ethics Committee of Affiliated Hospital of Chengde Medical College

\section{Consent for publication}

Not applicable.

\section{Competing interests}

The authors declare that they have no competing interests.

\section{Author details}

'Department of Rehabilitation, Affiliated Hospital of Chengde Medical College, Chengde, Hebei 067000, People's Republic of China. ${ }^{2}$ Trauma Department of Orthopedics, Affiliated Hospital of Chengde Medical College, 36 Nanyingzi Street, Shuangqiao District, Chengde, Hebei 067000, People's Republic of China.

Received: 24 June 2021 Accepted: 12 August 2021

Published online: 21 August 2021

\section{References}

1. St Clair JB, Schreiber VM. Supracondylar humerus fractures. Oper Tech Orthop. 2019;29(1):11-6. https://doi.org/10.1053/j.oto.2018.12.003.

2. Cheng JC, Lam TP, Maffulli N. Epidemiological features of supracondylar fractures of the humerus in Chinese children. J Pediatr Orthop B. 2001;10(1): $63-7$

3. Herzog MA, Oliver SM, Ringler JR, Jones CB, Sietsema DL. Mid-America Orthopaedic Association Physician in Training Award: Surgical Technique: Pediatric supracondylar humerus fractures: a technique to aid closed reduction. Clin Orthop Relat Res. 2013;471(5):1419-26. https://doi.org/10.1 007/s11999-012-2764-y.

4. Mulpuri $\mathrm{K}$, Hosalkar H, Howard A. AAOS clinical practice guideline: the treatment of pediatric supracondylar humerus fractures. J Am Acad Orthop Surg. 2012;20(5):328-30. https://doi.org/10.5435/JAAOS-20-05-328.

5. Sinikumpu JJ, Pokka T, Sirviö M, et al. Gartland type II supracondyla humerus fractures, their operative treatment and lateral pinning are increasing: a population-based epidemiologic study of extension-type supracondylar humerus fractures in children. Eur J Pediatr Surg. 2017;27(05): 455-61.

6. Holt JB, Glass NA, Bedard NA, Weinstein SL, Shah AS. Emerging U.S. national trends in the treatment of pediatric supracondylar humeral fractures. J Bone Joint Surg. 2017:99(8):681-7. https://doi.org/10.2106/JBJS.16.01209.

7. Patriota GSQA, Assunção Filho CA, Assunção CA. What is the best fixation technique for the treatment of supracondylar humerus fractures in children? Rev Bras Ortop. 2017;52(4):428-34. https://doi.org/10.1016/j.rbo.2016.08.015.

8. Dabash S, Gerzina C, Prabhakar G, Thabet AM, Jeon S, Heinrich SD, Screw fixation for supracondylar humerus fractures in children: a report of seventeen cases. Eur J Orthop Surg Traumatol. 2019:29(3):575-81. https:// doi.org/10.1007/s00590-018-2316-6.
9. Picado AV, Morán GG, Moraleda L. Management of supracondylar fractures of the humerus in children. EFORT Open Rev. 2018;3(10):526-40. https://doi. org/10.1302/2058-5241.3.170049.

10. Novais EN, Andrade MAP, Gomes DC. The use of a joystick technique facilitates closed reduction and percutaneous fixation of multidirectionally unstable supracondylar humeral fractures in children. J Pediatr Orthop. 2013;33(1):14-9. https://doi.org/10.1097/BPO.0b013e3182724d07.

11. Fletcher ND, Schiller JR, Garg S, et al. Increased severity of type III supracondylar humerus fractures in the preteen population. J Pediatr Orthop. 2012;32(6):567-72.

12. Wang YL, Chang WN, Hsu CJ, Sun SF, Wang JL, Wong CY. The recovery of elbow range of motion after treatment of supracondylar and lateral condylar fractures of the distal humerus in children. J Orthop Trauma. 2009 Feb;23(2):120-5. https://doi.org/10.1097/BOT.0b013e318193c2f3.

13. Taller $\mathrm{S}$. Use of external fixators in the treatment of supracondylar fractures of the humerus in children. Acta Chir Orthop Traumatol Cech. 1986;53(6): 508-14.

14. Gris M, OV N, Gehanne C, et al. Treatment of supracondylar humeral fractures in children using external fixation. Orthop. 2004:27(11):1146.

15. Bogdan A, Quintin J, Schuind F. Treatment of displaced supracondylar humeral fractures in children by humero-ulnar external fixation. Int Orthop. 2016:40(11):1-7.

16. Gugenheim JJ Jr. The llizarov fixator for pediatric and adolescent supracondylar fracture variants. J Pediatr Orthop. 2000;20(2):177-82. https:// doi.org/10.1097/01241398-200003000-00009

17. Slongo T. Lateral external fixation--a new surgical technique for displaced unreducible supracondylar humeral fractures in children. J Bone Joint Surge Am. 2008;90(8):1690-7. https://doi.org/10.2106/JBJS.G.00528.

18. Hohloch L, Konstantinidis L, Wagner FC, Strohm PC, Südkamp and NP, Reising K. Biomechanical evaluation of a new technique for external fixation of unstable supracondylar humerus fractures in children. Technol Health Care. 2015;23(4):453-61. https://doi.org/10.3233/THC-150905.

19. de Neira JZS, Prada-Cañizares A, Marti-Ciruelos R, et al. Supracondylar humeral fractures in children: current concepts for management and prognosis. Int Orthop. 2015;39(11):2287-96. https://doi.org/10.1007/s00264 015-2975-4

20. Jandrić S. Effects of physical therapy in the treatment of the posttraumatic elbow contractures in the children. Bosn J Basic Med Sci. 2007;7(1):29-32. https://doi.org/10.17305/bjbms.2007.3085.

21. Colović H, Stanković I, Dimitrijević L, et al. The value of modified DASH questionnaire for evaluation of elbow function after supracondylar fractures in children. Vojnosanit Pregl. 2008;65(1):27-32. https://doi.org/10.2298/ VSP0801027C.

22. Keppler $\mathrm{P}$, Khaled $\mathrm{S}$, Birte $\mathrm{S}$, et al. The effectiveness of physiotherapy after operative treatment of supracondylar humeral fractures in children. J Pediatr Orthop. 2005;25(3):314-6. https://doi.org/10.1097/01.bpo.0000153879.05314. d8.

23. Rove KO, Edney JC, Brockel MA. Enhanced recovery after surgery in children: promising, evidence-based multidisciplinary care. Paediatr Anaesth. 2018; 28(6):482-92.

\section{Publisher's Note}

Springer Nature remains neutral with regard to jurisdictional claims in published maps and institutional affiliations.

Ready to submit your research? Choose BMC and benefit from:

- fast, convenient online submission

- thorough peer review by experienced researchers in your field

- rapid publication on acceptance

- support for research data, including large and complex data types

- gold Open Access which fosters wider collaboration and increased citations

- maximum visibility for your research: over $100 \mathrm{M}$ website views per year

At BMC, research is always in progress.

Learn more biomedcentral.com/submissions 